\title{
2 Living with Multiple Sclerosis in Europe: Pharmacological Treatments, Cost of Illness, and Health-Related Quality of Life Across Countries
}

LARA GITTO

CEIS EEHTA (Economic Evaluation \& HTA), Università di Roma

"Tor Vergata," Roma, Italy

Author for correspondence: Lara Gitto, CEIS EEHTA (Economic Evaluation \& HTA), Università di Roma "Tor Vergata," Via Columbia 2, 00133 Roma, Italy. E-mail: Gitto@CEIS.uniroma2.it

Doi: http://dx.doi.org/10.15586/codon.multiplesclerosis.2017.ch2

Abstract: More than 700,000 people suffer from multiple sclerosis (MS) in Europe. This implies that more than 1 million people are affected by this disease through their role as caregivers and family members. Given its relevant impact, MS deserves consideration by epidemiologists, clinicians, psychologists, social scientists and other scholars. Such interdisciplinarity is stressed in the present contribution, which focuses on various aspects of socioeconomic burden. Starting from considerations about the epidemiology of the disease in Europe, as outlined by the MS Barometer, a comparative survey based on data collected by the national MS societies and launched in 2008, a brief literature review for each European country mentioned in the report was carried out with the following key terms: "multiple sclerosis," "cost of illness," and "health-related quality of life (HRQOL)." The consideration of the level of assistance provided, the access to rehabilitation centers, and the availability of pharmacological treatments,

In: Multiple Sclerosis: Perspectives in Treatment and Pathogenesis. Ian S. Zagon and Patricia J. McLaughlin (Editors), Codon Publications, Brisbane, Australia. ISBN: 978-0-9944381-3-3; Doi: http://dx.doi.org/10.15586/codon.multiplesclerosis.2017

Copyright: The Authors.

Licence: This open access article is licenced under Creative Commons Attribution 4.0 International (CC BY-NC 4.0). https://creativecommons.org/licenses/by-nc/4.0/ 
especially innovative therapies, reveal how there are still huge differences across Europe. Literature contributions are mostly oriented toward HRQoL studies and the impact of new pharmacological treatments. There are less studies focusing on compliance: this may be the consequence of a higher awareness of the disease among the patients and a strengthened cooperation with the physicians. Some suggestions about foreseeable and desirable lines of research conclude the contribution.

Key words: Cost of illness; European countries; Health-related quality of life; Multiple sclerosis; Pharmacological treatments

\section{Introduction}

More than 700,000 people suffer from multiple sclerosis (MS) in Europe; this implies that more than 1 million people are affected by this condition through their role as caregivers and family members (1). MS is one of the most common causes of neurological disability in young and middle-aged adults (2). It is characterized by various symptoms that can be associated with motor deficits (fatigue, paralysis, and coordination disturbances), sensory problems, speech and vision (blurred or double vision) impairments, and sphincter and bladder malfunctions (3). While MS can be diagnosed at any time in life, it frequently occurs between the ages of 20 and 40; women are more susceptible than men, with a ratio of 3:2. The natural history of MS is highly variable. Initially, about $85 \%$ of patients present with relapsing remitting multiple sclerosis (RRMS), which is characterized by unpredictable, self-limited episodes of the central nervous system, and may last from several days to weeks. For the remaining 15\% of patients, MS begins as primary progressive (PP) with the gradual worsening of neurological symptoms. Two-thirds of RRMS patients may develop a secondary progressive course (SPMS, secondary progressive multiple sclerosis), which is characterized by neurological deterioration over time (4). Although the disease may manifest and evolve in different ways, it definitely changes people's lives. Due to the consequences of MS, which go beyond the physical symptoms, patients have to limit their daily activities and social relationships, and their self-esteem might be reduced (5). Recent studies recognize how the number of people living with MS around the world is growing: it has increased at least by 10\% in the last few years, and in 2013 it reached 2.3 million (6). This is likely to be attributed mainly to diagnostic criteria such as the McDonald criteria, which permit to formulate a diagnosis more often than other criteria such as the Poser's criteria (7). There has been progress in brain imaging too: this leads to a faster diagnosis by employing a special type of scanning which is able to reveal lesions in the brain's white matter (8). The role and importance of information regarding MS as well as other chronic diseases have been stressed in many studies (9). Such information systems enable the identification, collection, and processing of data in order to obtain useful indications. Exchanging data among physicians and health care centers helps to organize better assistance. Hence, an accurate and efficient information system can reduce the expenses and uncertainties associated with the disease and favor an increase in health-related quality of life (HRQoL). 


\section{MS in Europe}

Currently, information regarding MS in Europe is widespread, thanks to many sources. The MS Barometer is a comparative survey based on data collected by the national MS societies (10). First launched in 2008, the MS Barometer raises awareness about the geographical differences in MS management across Europe. It is a questionnaire with points scored based on the responses: the higher the score, the better the disease management, the level of support, and the HRQoL of people with MS in each country. The questionnaire has been updated in three subsequent editions of the MS Barometer in 2009, 2011, and 2013. It is structured around the priority policy areas defined in the European Multiple Sclerosis Platform's (EMSP) Code of Good Practice, related to access to health care (where health care has to be meant as a comprehensive notion, which includes treatments, new medications accessing the market, therapies, and health workforce involved in MS care); research and data collection system (given that the quality of the information provided is likely to impact expenses determined by the disease); participation in society of people with MS (that aims at strengthening financial support, education for young people affected by MS, and possibility of employment); and empowerment (that should be meant as an objective both for people with MS and for organizations). Twenty-eight countries participated in the MS Barometer 2015, representing more than 500,000 patients. Hence, the MS Barometer 2015 sketched an up-to-date picture of prevalence, incidence, and access to treatment in Europe.

Instead, the EMSP, founded in 1989, group about 40 national MS member societies from 35 European countries and aims at collecting data and evidence on MS with the purpose of being a guide to improve patients' and their families' HRQoL.

Table 1 reports on data about MS prevalence across European countries, collected through the national MS societies joining the EMSP. Further evidence is presented in Table 2, which contains data collected by the EMSP (11), retrieved through the Atlas of MS (www.atlasofms.org), the report Under Pressure, Living with MS in Europe, released by the EMSP (www.underpressureproject.eu) and some recent studies $(1,12)$. Data are representative of the year 2013 and relate to prevalence and access to disease-modifying drugs (DMDs) and symptomatic treatments, which will be discussed in more detail in the next section. Other information concerns epidemiological data on the course of MS (age of diagnosis, RR form); the impact on working (percentage of reduction in the number of working hours and the percentage of people with MS employed part time and full time); information related to the social impact of the disease such as the awareness of the disease, limitations at work, and the possibility to access rehabilitation centers. This information sheds light on the level of assistance, especially provided to patients experiencing a relapse and the possibility to recover from it. Little information was available for countries such as Cyprus, Latvia, and Slovakia. Overall, there are important consequences for individuals' working activity: on average, half of the people with MS leave their jobs 3 years after the diagnosis (13).

Costs, employment, and quality of life are affected by increasing disease severity in people with MS $(14,15)$. While, in the early stages of the disease, costs are predominantly driven by pharmacological treatments, when the 


\section{TABLE 1 MS in European Countries (in ascending order of prevalence)}

\begin{tabular}{|c|c|}
\hline Country & Prevalence per 100,000 \\
\hline Slovakia & NA \\
\hline Romania & 30 \\
\hline Bulgaria & 39 \\
\hline Portugal & 56 \\
\hline Croatia & 59 \\
\hline Greece & 70 \\
\hline Lithuania & 78 \\
\hline Estonia & 82 \\
\hline The Netherlands & 88 \\
\hline Latvia & 90 \\
\hline France & 95 \\
\hline Belgium & 100 \\
\hline Spain & 102 \\
\hline Finland & 105 \\
\hline Switzerland & 110 \\
\hline Italy & 113 \\
\hline Poland & 120 \\
\hline Slovenia & 120 \\
\hline Austria & 140 \\
\hline Ireland & 140 \\
\hline Germany & 149 \\
\hline Czech Republic & 160 \\
\hline Norway & 160 \\
\hline United Kingdom & 164 \\
\hline Cyprus & 175 \\
\hline Hungary & 176 \\
\hline Sweden & 189 \\
\hline Denmark & 227 \\
\hline
\end{tabular}

Source: European Multiple Sclerosis Platform, 2015.

$\mathrm{NA}=$ not available 


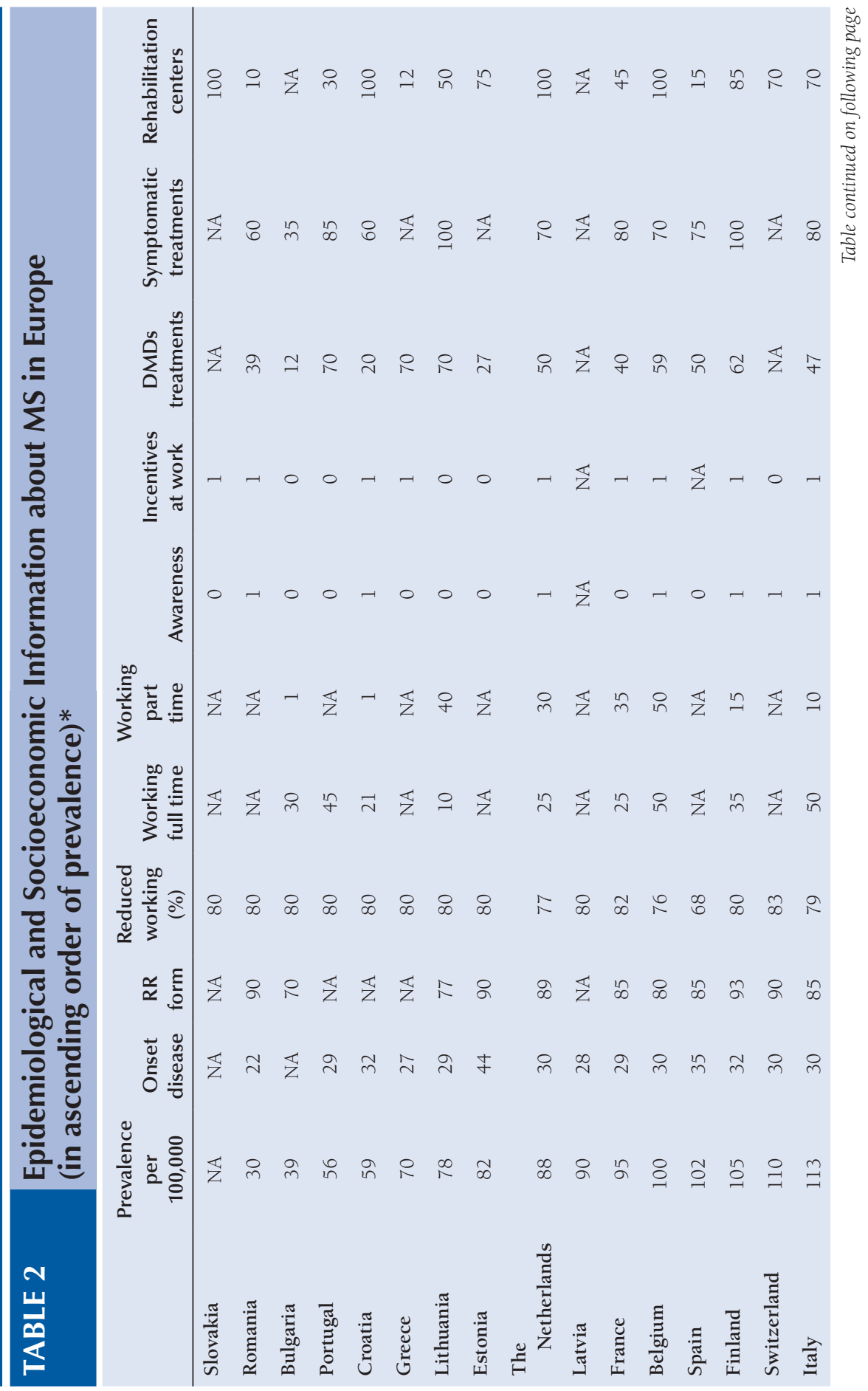




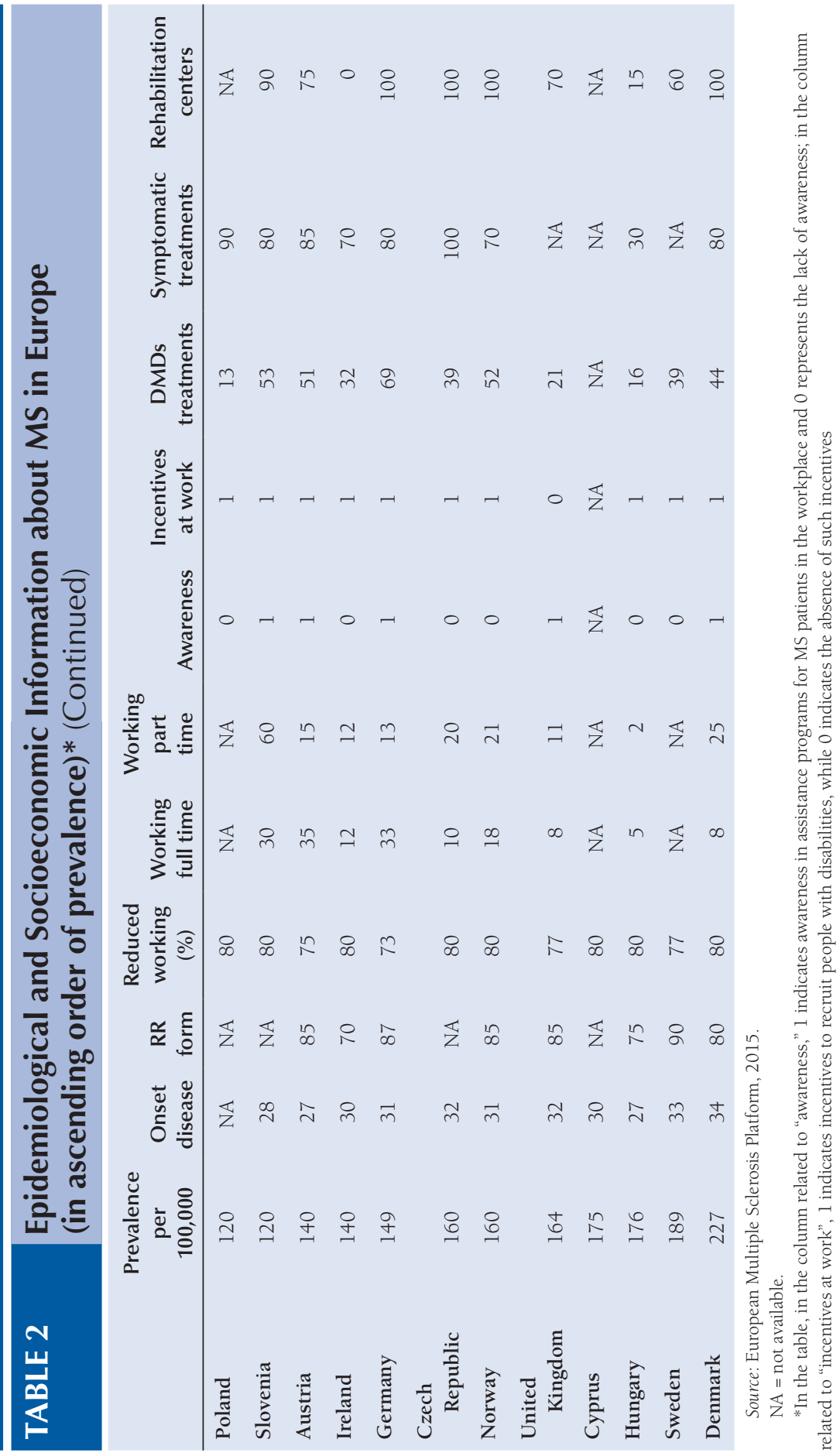


disease becomes severe, the overall costs increase, and indirect costs (due to the loss of productivity for patients and their caregivers) become more significant. It has been estimated that the average cost per year of all resources relating to MS was $€ 22,800$ for those patients with mild disease severity, $€ 37,100$ for those with moderate disease severity, and $€ 57,500$ for those patients with severe disease (14). The same study outlined how, among people of working age, $18 \%$ of patients with mild disease were unemployed; this percentage is about $92 \%$ when people with severe disease are considered. Disability is the main driver of reduced productivity and HRQoL; the symptoms due to the disease that impact productivity are fatigue (experienced on average by $95 \%$ of patients considered for the study) and cognitive difficulties (experienced by $71 \%$ of patients). Data about employment, according to the information provided by EMSP, were not available for Cyprus, Greece, Portugal, Spain, Sweden, Switzerland, and eastern European countries (Estonia, Latvia, Poland, Romania, and Slovakia). With the exception of Belgium and Slovenia, where more than $50 \%$ of the people with MS are employed full time, this percentage, overall, is not very high (in Denmark and the United Kingdom, people with MS working full time are, respectively, 8 and 5\%). However, data are fragmented and apparently contrasting; for example, Austria, Bulgaria, Croatia, and Hungary present a percentage of people employed part time that is lower compared with people employed full time. Incentives to recruit disabled people are present in the majority of countries, with some exceptions such as Bulgaria, Estonia, Lithuania, Portugal, Switzerland, and the United Kingdom. Such incentives are often coupled with the awareness in programs on MS for the workplace and information directed to employers, coordinated by public or private institutions (according to the evidence reported, this occurs in Austria, Belgium, Croatia, Denmark, Finland, Germany, Italy, the Netherlands, Romania, and Slovenia).

Poland and Hungary have the lowest access to DMDs treatment. In Belgium, Croatia, Czech Republic, Denmark, Germany, the Netherlands, Norway, and Slovakia, 100\% of MS patients have access to rehabilitation centers.

The evidence that emerges from the table, which summarizes the information retrieved from several sources, stresses which issues should be investigated in more detail. First of all, information on the labor market and the social consequences for MS patients should be enriched. Loss of productivity due to illness, which, according to data, is $79 \%$ (average data), leads to an increase in indirect costs and higher social costs, and this has to be investigated. There are not many studies that have been concerned with this aspect, neither are there detailed analyses on the costs of the disease, including indirect costs and productivity losses (16). Finally, affordability is a key barrier to access MS products. In some countries, patients cannot afford the cost of treatment and the expenses related to the disease. Hence, the organization of an efficient assistance model is crucial.

\section{Treatments for MS}

There is no definitive cure for MS as yet, but access to pharmacological preventive and symptomatic treatments may help patients in managing the disease $(17,18)$. 
An early recognition of the inflammatory process allows patients to begin treatment with a DMD even before the technical diagnosis of definite MS; in this way, the degenerative progression of MS can be delayed (16). It has been shown how patients, who had started the treatment at a later stage, had a greater risk of reaching score 4 on the Expanded Disability Status Scale (EDSS). Although this is a moderate disability score (while EDSS scores higher than 4.5 are regarded as more severe, impairing individuals' daily activities), according to clinical evidence, this may increase by $7.4 \%$ for every year of delay in treatment start after MS onset (19). Moreover, the early pharmacological treatment is associated with fewer hospitalizations, a reduction of relapses, and a gain of QALYs than delayed treatment $(20,21)$.

The choices about the most suitable pharmacological treatment and its timing may rely on the patient's and physician's joint decision $(2,22)$. However, the treatment selected and the type of assistance provided to MS patients depend mostly on the characteristics of the health system in each country. Although many studies have found that a consistent part of costs caused by MS is related to productivity losses (sick leave and early retirement due to MS), nonmedical costs (devices and investments to adapt living conditions) and informal care by family and friends (23), it has been estimated that, on average, more than $50 \%$ of the costs associated with the disease come from direct medical costs, which are often due to innovative therapies. The relevance of drug treatment and the weight attributed to pharmaceutical costs have to be considered from the third payer's and societal perspectives. New treatments have been made available in recent years. Innovative drugs are still under development or waiting for approval within a centralized procedure by the European Medicines Agency or through a decentralized procedure, at the national-level reference.

About the type of therapies for MS currently available, disease-modifying therapies (DMTs) include injectable medications (interferon beta $1-\mathrm{a}$ and $1-\mathrm{b}$, glatiramer acetate, and peginterferon beta 1a), oral medications (fingolimod, teriflunomide, and dimethyl fumarate), and infused medications (natalizumab and alemtuzumab). In addition, there are other treatments with immunosuppressants that can be effective for MS (mitoxantrone, azathioprine, cyclophosphamide, methotrexate, etc.). Other drugs (e.g., corticosteroids or nabiximols) are employed in case of relapse or to alleviate some symptoms of MS. All these agents act by modulating and/or suppressing the immune system at various levels with different mechanisms of action. The efficacy, tolerability, and safety profile vary significantly across treatments, ranging from combinations of modest effect and a good level of safety to those that are highly effective but at increased risk of serious or even fatal adverse events.

First-line treatments are intended as a moderate-efficacy, high-safety drug and include interferon beta $1 \mathrm{a}$ and $\mathrm{lb}$, glatiramer acetate, peginterferon beta la, teriflunomide, and dimethyl fumarate. Differences exist in terms of efficacy and tolerability among first-line drugs, although direct comparison data are limited (22). Second-line treatments are used in case of unsatisfactory response to first-line drugs: they are not only more effective but also come with more safety risk, and include, among others, natalizumab, alemtuzumab, and mitoxantrone. Fingolimod is approved as a second-line treatment in the European Union and as a first-line treatment in the United States, Canada, and other countries (22). Azathioprine and cyclophosphamide, which are not registered as treatment for MS, are used as first-line and second-line medications, respectively. 
There have been many studies on access to MS treatments in Europe. A wellknown study (24) looked at the available evidence on prevalence, the costs to society, and difference in access across European countries, and discusses the determinants of patients' access itself. The authors found that there was a wide variation across European member states: according to 2008 data, in Western Europe around $44 \%$ of patients had access to pharmacological treatment, whereas in Central and Eastern Europe, this percentage was between 6 and $42 \%$. Such large variations in the number of patients with access to innovative drugs could be explained by economic differences among European economies that lead to a diverse range of pharmacological treatments guaranteed to patients by each national health system. However, the authors of the study found that price levels did not reflect the affordability levels in different markets. Indeed, they also identified differences in medical practice, the ease of access to care, and the availability of care.

The access to innovative treatments across European countries may depend on health policy issues too: some countries may focus on a particular MS patient sub-population and develop specific treatment guidelines. Hence, depending on where a patient lives, he or she will be, or will not be, entitled to such medication. For example, in Sweden, for the use of immunomodulatory therapy, approximately $75 \%$ of patients with RRMS meet the criteria for DMDs therapy. Moreover, Sweden presents a high number of SPMS patients: in this light, a study aimed at comparing first-line and second-line treatments, such as natalizumab and fingolimod, outlined how Scandinavian countries provide better access to innovative second-line treatments, followed by France, Austria, and Belgium. Overall, the access to pharmacological treatment has increased in the past years. The percentage of people treated with DMDs across European countries is shown in Figure 1. Among these patients, the percentage of those who are accessing the most innovative treatments is estimated at around 20\% for MS patients in Europe. Instead, in eastern European countries, lower shares can be observed: in 2008, in Poland and Romania, around 3-4\% of the patients with MS had access to innovative therapies.

\section{Medical and Socioeconomic Literature Related to MS: Evidence from the Literature in the Countries Joining the MS Barometer}

The studies investigating the prevalence of MS across Europe include countryspecific studies, cross-country comparisons, and compendia of prevalence statistics. Wilsdon et al. (25) cite, among the international comparisons, Kingwell et al. (26), who carried out a systematic review of incidence and prevalence of MS in Europe between 1985 and 2011. The authors concluded that prevalence and incidence estimates tended to be higher in the more recent studies, especially in the Nordic countries; they also stated that, despite the extent of the literature on the epidemiology of MS in Europe, inter-study comparisons are hindered by the lack of standardization. With the general aim of establishing a Europe-wide platform for systematic analysis and comparison of longitudinally collected MS data in 


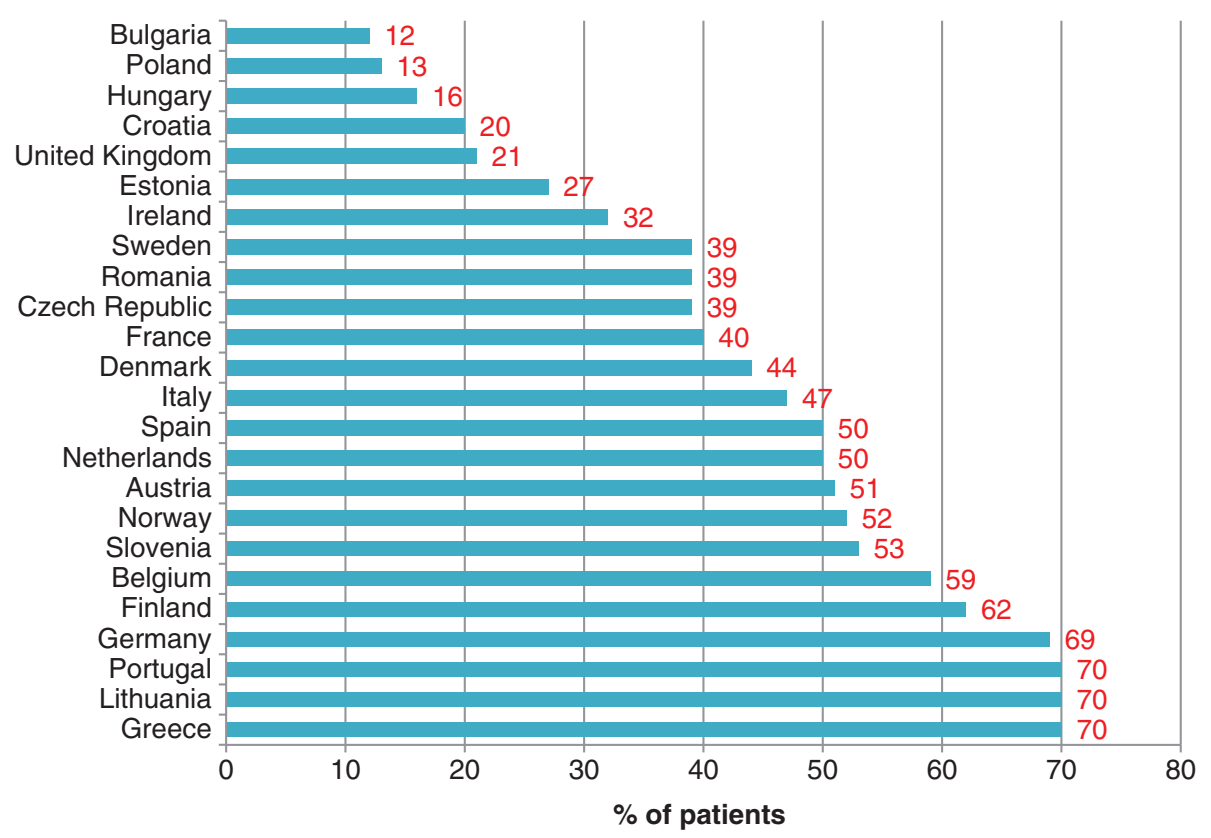

Figure 1 Percentage of MS patients who have access to DMDs in Europe.

Source: CRA Analysis, 2014.

Europe, the European Register for Multiple Sclerosis (EUReMS) project was started in 2010 by an international consortium, involving both scientists and patient organizations (27). Detailed information about the number and content of national MS registries in Europe is needed to facilitate the integration of existing data, as well as to carry out comprehensive analyses and comparison across European populations.

In a systematic review of MS registries and databases in Europe, a detailed search identified 17 national MS registries, adding to this list three other registries after contacting European MS societies (28). The registries differ with regard to objectives, structure, data, and the number and type of patients included. In spite of their heterogeneity, all registries had the following common objectives: MS epidemiological and pharmacological surveillance; efficacy, safety, and cost-effectiveness of pharmacological treatments in the long run; provision and quality of health care services; HRQOL and other socioeconomic aspects, such as the burden of disease, both from the patients' perspectives and that of the neurological centers. According to the study findings, registries were available for Austria, Bosnia and Herzegovina, Croatia, Czech Republic, Denmark, France, Germany, Greece, Iceland, Italy, Malta, the Netherlands, Norway, Slovenia, Spain (Catalonia), Sweden, and the United Kingdom.Further information was collected through the national MS societies of Russia, Serbia, and Switzerland. 
A literature search for each European country included in the MS Barometer was then carried out in PubMed (period 2012-2017; last accessed, May 20, 2017) using the terms 'multiple sclerosis + country', then 'multiple sclerosis + country + cost of illness' and, finally, 'multiple sclerosis + country + health related quality of life'. Although they are not fully comprehensive, the results gave a picture of the aspects that have received more attention in the 28 European countries considered. Overall, it was noted that MS is often treated in the literature together with other chronic conditions (especially in the studies focusing on HRQoL and carried out at the European level). In some countries, many studies have been carried out within international research projects aimed at assessing the cost-effectiveness and cost-utility ratio for pharmacological treatments, or directed at developing common guidelines and assistance protocols.

The review could be improved by mentioning other aspects in the epidemiology and management of the disease, focusing on cost of illness (COI) and looking at indirect costs that are related to MS patients' reduced productivity and HRQoL. The countries observed through the Barometer, in alphabetical order, are: Austria, Belgium, Bulgaria, Croatia, Cyprus, Czech Republic, Denmark, Estonia, Finland, France, Germany, Greece, Hungary, Ireland, Italy, Latvia, Lithuania, the Netherlands, Norway, Poland, Portugal, Romania, Slovakia, Slovenia, Spain, Sweden, Switzerland, and the United Kingdom.

In Austria, treatment registries, especially for pharmacological "second-line" treatments, such as Fingolimod and Natalizumab, have been instituted. A general search on epidemiology of MS found 314 studies, of which the most recent are focused on the impact of emerging drugs such as ocrelizumab (29). Other economic evaluation analyses concern socioeconomic aspects of some treatments (30). Studies related to QoL have considered some specific rehabilitation programs aimed at improvements in the specific domains of attention and mental fatigue (31).

In Belgium, most of the studies retrieved were clinical and were carried out within European research projects. There is a national registry for MS, the Beltrims, started in 2012. Organizational issues have been discussed in studies assessing the costs and potential financial benefits of integrated care models for patients with chronic diseases (32). The total burden of the disease relates to the clinical, humanistic, and economic dimension. Crucial information is still missing about MS pathophysiology and other clinical issues. This is a hindrance in reaching the objective of an equal access to care and treatment for MS.

Bulgaria does not have a tradition of studies on MS. Only in 2017, the Bulgarian MS Society announced the realization of a registry of patients (http://www.emsp. org/news-messages/ms-registry-and-national-representation/). The literature search found only 16 studies, of which the last epidemiology study was in 1997 (33), and reported a considerably lower prevalence of MS in Bulgaria comparing with the neighboring countries.

Cyprus neither has any information on epidemiology of MS nor any record based on scientific evidence. The official data of prevalence and/or incidence refers to the information reported by the Atlas of MS 2013; the studies that have been identified through the research were mainly related to the clinical impact of MS or they were meta-analyses $(34,35)$. 
In Croatia, the studies carried out in the last 5 years focused mainly on pharmacological treatments and diagnostic tools such as magnetic resonance (36). Croatia has a national registry for MS, started in 2007.

The Czech ReMuS started in 2013. The output of the ReMuS is published regularly (http://www.multiplesclerosis.cz/docs/160929_remus_aj_zaverecna-zprava 2016_06_souhrnna.pdf). One COI study used Czech data and extrapolated to Polish patients to estimate costs of MS (37). The mean annual costs from societal and payers' perspective were calculated for patients according to EDSS. Indirect costs (production loss due to early retirement, sick leave, and informal care) cover up to $70 \%$ of total costs.

In Denmark, all cases of MS have been registered since 1948. In 1996, the Danish MS Treatment Registry was established. Most of the studies adopted a multidisciplinary perspective of MS, with focus on the organization of a multidisciplinary care team and the possibility to support the patient, so that the latter is empowered to manage his or her disease and to implement a physically active lifestyle. Furthermore, some studies have emphasized how dedicated programs for patients and health care professionals, including nonmedical treatment strategies, should be developed at the European level (38).

In Estonia, statistical and updated data about MS is not yet available (see http://www.smk.ee/tooandjatele/statistika/). One clinical study, carried out at West-Tallinn Central Hospital, was retrieved (39).

In Finland, the focus has recently been on the new therapies (40), the estimation of patients' costs and HRQoL, and cognitive deficits. Although the incidence and prevalence of MS in Finland are high and the structure of the Finnish health care is ideal for taking care of MS, Finland was the only Scandinavian country without a national MS register until 2011. The Finnish Neurological Association assigned a steering board to develop an MS national registry. By 2016, five university hospitals and six central hospitals have joined the register. The burden of illness and HRQoL have constituted the topic of some recent analyses (41, 42).

In France, the MS registry is sponsored by the Hospices Civils de Lyon. At the end of 2015, it observed 54,000 patients. One of the latest studies provided estimates of the prevalence and mortality rate of MS and used reimbursement data for disease-modifying treatment, long-term disease status, disability pension, and hospitalization (43). Another study analyzed the social participation in patients with MS, correlating economic costs related to the treatment with social participation, utility, and MS-specific quality of life in a sample of 42 patients receiving natalizumab (44).

In Germany, the national MS registry was established in 2001. In the last 5 years, a large number of studies have come out of Germany (about 2063 studies). Despite this, health care utilization data and analyses for MS are still scarce (45). Some studies (46) were related to the effects of new treatments such as alemtuzumab on safety, effectiveness, and HRQoL.

The largest number of researches carried out in Greece, where there is a national MS registry, concern clinical issues. There are no recent prevalence studies; the last one dates back to 2008 (47). Some interesting insights came from studies aimed at defining a sort of "stigma" for MS patients, especially neurological disorders, that determines the exclusion from full social acceptance. Although stigma is considered to be present in MS, the factors that influence its levels are ambiguous (48). About the COI analyses carried out for Greece, 
the search outlined how there is a North-South gradient for health expenditure for costs and prevalence of the disease (49). The authors of the study stress how health and welfare systems of some countries are not prepared to manage these occurrences. HRQoL is treated in a study that outlines how HRQoL is influenced by self-confidence, which is a direct result of self-ability and mobility, the stage of disease, the social relations, and the risk of sudden substantial of health deterioration (50).

There is no national registry for MS in Hungary, but some data are provided by the Hungarian MS Society, established in 1988 (http://www.smtarsasag.hu/). Prevalence studies are related to single centers or to counties. The first epidemiological study on MS was based on the McDonald diagnostic criteria in central Europe (51). There is only one COI study (52) that is aimed at exploring the quality of life, resource utilization, and costs of 68 MS patients in Hungary. About 16 studies focused on the effects of the disease symptoms on HRQoL; a recent study (53) examined the correlations between HRQoL and the level of disability, fatigue, and depression in glatiramer acetate-treated patients with MS and provided suggestions for the management of the disease, recommending immunomodulatory therapy together with improvements of the diagnostics and treatment of the accompanying depression.

Ireland has a high prevalence of MS, which has been increasing in the last 20 years. There is no national registry of people with MS. There are, however, patients' associations which provide an insight into the number of people with MS. Among the first studies aimed at prospectively assessing the incidence rate of MS in Ireland, one epidemiological study ascertained all new cases of MS in the years 2014 and 2015 (54). Another research (55) shows how MS can be associated with significant disability, resulting in considerable socioeconomic burden for both patients and the society. The study found that even low-intensity episodes can have a significant financial impact for the patient. In a prospective study, it has been outlined how there is the potential to significantly reduce the economic burden of the disease through interventions that prevent progression from mild or moderate MS to severe MS, and keep people in the work force (56). A HRQoL study, using EQ-5D-5L correlation with the EDSS score, showed a linear decline in utility with changes in EDSS from 0 to 6, after which point the relationship exhibited greater variability (57).

In Italy, the studies on MS are related to various topics, such as clinical outcome, cost-effectiveness analyses, and rehabilitation. Some Italian regions (such as Sicily, in the South) have recently initiated their MS registries. The Associazione Italiana Sclerosi Multipla (AISM) provides data about the prevalence and incidence of MS in Italy. A crucial aspect, during the last few years, has been that of adherence and compliance to pharmaceutical treatments as well as communication $(58,59)$. COI studies are often carried out together with costutility analyses and Quality of Life Surveys $(60,61)$. The focus of the literature is on new therapeutic options as well as the progressive forms of the disease; some research projects concerning palliative approaches to severe MS or communication in SP MS are being carried out (62).

Latvia is often included in international studies on MS among other countries. The national association was instituted in 1995 (http://mslapa.lv/site/30146).

In Lithuania, a multicenter MS registry was created in 2013 and the data collection was started in three MS centers and university hospitals. Most of 
the studies are related to the experience of single centers and the effectiveness of therapies and adherence (63); other studies relate to specific MS disturbances (64).

The studies carried out in the last 5 years in the Netherlands are mainly clinical, evaluating symptoms and the effects of pharmacological treatments. The NEDBase, the national Dutch registry, started in 2007 involves six neurological centers. Some comprehensive studies have measured the burden imposed by MS on the Dutch society, which is higher compared to the results of previous studies (65). Recent studies examine both adherence and persistence and outline how the latter could be predicted by HRQoL (66).

Most recent studies carried out in Norway focus on risk factors for MS, mortality data, and life expectancy (67-69). In Norway, there is a national MS registry.

In Poland, the National Registry of MS patients was created in 2013 (70). The literature has focused both on COI and HRQoL studies. A study based on real-life data from the Social Insurance Institution in Poland has assessed the indirect costs of six major autoimmune diseases, concluding that MS is associated with great indirect costs (71). Studies on HRQoL employ data from the Polish registry and examine the role of cognitive appraisals, adjusted for clinical, socioeconomic, and demographic variables, as correlates of HRQoL in MS $(72,73)$.

In Portugal, the National Society for MS was established in 1984. Although the literature search retrieved 216 studies, the last epidemiological study was in 2010 (74). There are no studies focused on COI; however, Portugal is often analyzed within international studies (48). Other studies looked at several problems associated with the disease, such as sleep disturbances (75).

In Romania, there is a national association of MS patients, which was founded in 1995. Epidemiological studies were carried out in 1989 and 1994 $(76,77)$. Another study, related to the Multiple Sclerosis Information Dividend (MS-ID) project, aimed at identifying and addressing major inequalities of MS treatment and care, was carried out in 2010 (78): it considered the feasibility of an EU MS register among five countries (Germany, Iceland, Poland, Romania, and Spain).

The Slovakian Association for MS was founded in 1990. The studies are mainly clinical or aimed at assessing cognitive impairment determined by MS (79). COI has been investigated in few studies. An MS study in 2015 in Slovakia was the first Slovak study to provide information about health care, social expenditure, and the cost of productivity loss; direct and indirect costs of MS were retrospectively analyzed by prevalence, based on a bottom-up approach (80). The societal and health insurance perspective was used to assess the economic burden caused by MS in Slovakia, using the human capital method for the calculation of indirect costs. HRQoL has been the object of another study that evaluated functional disability measured by patients and neurologists (81).

In Slovenia, the national MS association was established in 1973. Most of the studies related to MS focused on the effects of pharmacological treatments. One international multicenter study concerned physiotherapy and rehabilitation (82). HRQoL together with coping was investigated as well (83).

Spain is often mentioned in international studies carried out for Europe and related to treatment experience and MS burden of disease. There is a MS registry for Catalonia. Other registries follow patients in treatments with given drugs, 
for example, Fingolimod (84). The most recent studies regard prevalence of MS and suggest an increasing prevalence (85). Several works estimate the COI of MS (86), measure its socioeconomic effects (87), or carry out budget impact analyses (88).

In Sweden, there has been a National Registry of MS patients since 1997; many studies are based on real-life data. Prevalence of MS has been analyzed in different areas of the country (89). There are several recent studies on COI that have been carried out for working-aged individuals, reporting that indirect costs contributed to approximately $75 \%$ of the estimated costs of MS patients (90). Costs and utility are highly correlated with disease severity, and resource consumption may be influenced by health care systems' organization and availability of services (12). The studies on HRQoL are aimed at assessing several aspects of the pathology, in particular, relapses associated with increased fatigue and reduced HRQoL (91).

The Swiss society for MS instituted a register in 2016 (https://www.multiplesklerose.ch/it/attualita/dettaglio/registro-svizzero-sm-partecipanti-colpitidi-ogni-eta/). The perspectives and expectations of MS patients have been analyzed in a study that outlined how there is no data available about the needs of people living with MS in Switzerland (92). Other studies, related to HRQoL, carried out by Swiss researchers, however, do not employ Swiss data (93).

In the United Kingdom, the MS registry was started in 2009. Through the literature research, it was possible to retrieve about 1000 studies. Together with incidence and prevalence (94), studies related to cost-effectiveness, cost utility analyses, and prognostic factors have been carried out (95).

\section{Conclusion}

The studies carried out on MS in Europe are mostly oriented toward HRQoL and the impact of new pharmacological treatments. There are less studies focusing on compliance: this may be a consequence of the higher awareness of the disease among the patients and a strengthened cooperation with the physicians. The consideration of the level of assistance provided, the access to rehabilitation centers, and the availability of pharmacological treatments, especially innovative therapies, reveal how there are still huge differences across Europe. The scholars' effort should be directed toward the estimation of the burden of disease and the strategies to implement for the achievement of a higher HRQoL. In spite of many studies on the epidemiological course of the disease, these aspects have not been fully exploited yet, and they need more attention. Costs, employment status, and quality of life are closely linked to disease severity across European countries. In this perspective, the development of a common strategy is essential to ensure consistency in the quality of care over time, to address the variations in service provision for people with MS, and to provide a framework to get access to innovative therapies more rapidly. National registries, linked to an EU comprehensive registry (EUReMS), need to be developed in order to measure the prevalence of MS across countries and to assess the status of people with MS. It is also important that clinical guidelines are kept up to date and, more importantly, that they are actually used in practice. 
Conflict of interest: The author declares no potential conflicts of interest with respect to research, authorship, and/or publication of this chapter.

Copyright and permission statement: To the best of my knowledge, the materials included in this chapter do not violate copyright laws. All original sources have been appropriately acknowledged and/or referenced. Where relevant, appropriate permissions have been obtained from the original copyright holder(s).

\section{References}

1. European Multiple Sclerosis Platform. Under pressure. Living with multiple sclerosis in Europe [Internet]. 2013. Available from: http://www.underpressureproject.eu/web/living-with-ms-in-europe

2. Gitto L. Multiple Sclerosis patients' awareness of disease and compliance to pharmacological treatment with Disease Modifying Drugs (DMDs). Eur J Pers Cent Healthc. 2016 Dec;4(4):599-608.

3. Noseworthy JH, Lucchinetti C, Rodriguez M, Weinshenker BG. Multiple sclerosis. New Engl J Med. 2000 Sep 28;343(13):938-52. http://dx.doi.org/10.1056/NEJM200009283431307

4. Kantarci OH, Weinshenker B. Natural history of multiple sclerosis. Neurol Clin. 2005 Feb; 23(1):17-38. http://dx.doi.org/10.1016/j.ncl.2004.10.002

5. Coyne KS, Boscoe AN, Currie BM, Landrian AS, Wandstrat TL. Understanding drivers of employment changes in a multiple sclerosis population. Int J MS Care. 2015 Sep-Oct;17(5):245-52. http://dx.doi. org/10.7224/1537-2073.2014-051

6. Hirschler B, Lyon A. Global multiple sclerosis cases increase $10 \%$ in last 5 years. The Huffington Post Healthy Living [Internet]. 2013. Available from: http://www.huffingtonpost.com/2013/10/02/ multiple-sclerosis-cases-world-global-increase_n_4026308.html

7. Fangerau T, Schimrigk S, Haupts M, Kaeder M, Ahle G, Brune N, et al. Diagnosis of multiple sclerosis: Comparison of the Poser criteria and the new McDonald criteria. Acta Neurol Scand. 2004 Jun;109(6):385-9. http://dx.doi.org/10.1111/j.1600-0404.2004.00246.x

8. University of Nottingham. New MRI technique offers faster diagnosis of multiple sclerosis. Science Daily. 2016, February 1 [Internet]. Available from: www.sciencedaily.com/releases/2016/02/160201125504. htm

9. Ajami S, Ahmadi G, Etemadifar M. The role of information system in multiple sclerosis management. J Res Med Sci. 2014 Dec;19(12):1175-84.

10. European Multiple Sclerosis Platform. MS Barometer 2015. Raising the voice of people with MS [Internet]. Available from: http://www.emsp.org/wp-content/uploads/2017/02/BAROMETER-2015-28.02.2017. pdf

11. European Multiple Sclerosis Platform. Multiple sclerosis in Europe 2015 [Internet]. Available from: http://www.emsp.org/wp-content/uploads/2015/08/MS-in-EU-access.pdf

12. Kobelt G, Thompson A, Berg J, Gannedahl M, Eriksson J, The MSCOI Study Group, et al. New insights into the burden and costs of multiple sclerosis in Europe. Mult Scler 2017;23(8):1123-36. http://dx.doi.org/10.1177/1352458517694432

13. Messmer Uccelli M, Specchia C, Battaglia MA, Miller DM. Factors that influence the employment status of people with multiple sclerosis: A multi-national study. J Neurol. 2009 Dec;256(12):1989-96. http://dx.doi.org/10.1007/s00415-009-5225-0

14. Kobelt G. Health economic issues in MS. Int MS J. 2006 Jan;13(1):17-26, 16.

15. Mennini FS, Marcellusi A, Viti R, Russo S, Gitto L. Cost of illness della sclerosi multipla in Italia. Presented at the conference "La gestione globale del paziente con Sclerosi Multipla", BEMS (Best Evidence in Multiple Sclerosis), Milano, 11 May 2017.

16. Miller JR. The importance of early diagnosis of multiple sclerosis. J Manage Care Pharm. 2004 Jun;10(3 Suppl B):S4-11.

17. Mayo Clinic. Multiple sclerosis. Treatment [Internet]. 2017. Available from: http://www.mayoclinic. org/diseases-conditions/multiple-sclerosis/diagnosis-treatment/treatment/txc-20131903 
18. Schapiro RT. The symptomatic management of multiple sclerosis. Ann Indian Acad Neurol. 2009 Oct;12(4):291-5. http://dx.doi.org/10.4103/0972-2327.58278

19. Kavaliunas A, Manouchehrinia A, Stawiarz L, Ramanujam R, Agholme J, Hedström AK, et al. Importance of early treatment initiation in the clinical course of multiple sclerosis. Mult Scler. 2017 Aug;23(9):1233-1240.

20. Castrop F, Haslinger B, Hemmer B, Buck D. Review of the pharmacoeconomics of early treatment of multiple sclerosis using interferon beta. Neuropsychiatr Dis Treat. 2013;9:1339-49. http://dx.doi. org/10.2147/NDT.S33949

21. Curkendall SM, Wang C, Johnson BH, Cao Z, Preblick R, Torres AM, et al. Potential health care cost savings associated with early treatment of multiple sclerosis using disease-modifying therapy. Clin Ther. 2011 Jul;33(7):914-25. http://dx.doi.org/10.1016/j.clinthera.2011.05.049

22. Gajofatto A, Benedetti MD. Treatment strategies for multiple sclerosis: When to start, when to change, when to stop? World J Clin Cases. 2015 Jul;3(7):545-55.

23. Kobelt G, Berg J, Lindgren P, Fredrikson S, Jönsson B. Costs and quality of life of patients with multiple sclerosis in Europe. J Neurol Neurosurg Psychiatry. 2006 Aug;77(8): 918-26. http://dx.doi. org/10.1136/jnnp.2006.090365

24. Kobelt G, Kasteng F. Access to innovative treatments in multiple sclerosis in Europe. Report prepared for the European Federation of Pharmaceutical Industry Associations (EFPIA) 2009. Available from: http://www.comparatorreports.se/Access\%20to\%20MS\%20treatments\%20-\%200ctober\%202009. pdf

25. Wilsdon T, Barron A, Mitchell Heggs A, Ginoza S. Access to medicines for multiple sclerosis: Challenges and opportunities. Charles River Associates (CRA) 2014 [Internet]. Project No. D19380. Available from: https://www.crai.com/sites/default/files/publications/CRA-Biogen-Access-to-MSTreatment-Final-Report.pdf

26. Kingwell E, Marriott JJ, Jetté N, Pringsheim T, Makhani N, Morrow SA, et al. Incidence and prevalence of multiple sclerosis in Europe: A systematic review. BMC Neurol. 2013 Sep;13:128. http://dx.doi. org/10.1186/1471-2377-13-128

27. European Multiple Sclerosis Platform. European Register EuReMS 2015 [Internet]. Available from: http://eurems.eu/

28. Flachenecker P, Buckow K, Pugliatti M, Kes VB, Battaglia MA, Boyko A, et al. Multiple sclerosis registries in Europe-Results of a systematic survey. Mult Scler. 2014 Oct;20(11):1523-32. http://dx.doi. org/10.1177/1352458514528760

29. Deisenhammer F, Auer M, Hegen H. Ocrelizumab in primary progressive and relapsing multiple sclerosis. N Engl J Med. 2017 Apr;376(17):1693-4.

30. Walter E, Deisenhammer F. Socio-economic aspects of the testing for antibodies in MS-patients under interferon therapy in Austria: A cost of illness study. Mult Scler Relat Disord. 2014 Nov;3(6):670-7. http://dx.doi.org/10.1016/j.msard.2014.09.003

31. Pusswald G, Mildner C, Zebenholzer K, Auff E, Lehrner J. A neuropsychological rehabilitation program for patients with MS based on the model of the ICF. NeuroRehabilitation. 2014:35(3):519-27.

32. Desmedt M, Vertriest S, Hellings J, Bergs J, Dessers E, Vankrunkelsven P, et al. Economic impact of integrated care models for patients with chronic diseases: A systematic review. Value Health. 2016 Sep-Oct;19(6):892-902. http://dx.doi.org/10.1016/j.jval.2016.05.001

33. Milanov I, Georgiev D, Kmetska K, Jordanova L, Topalov N. Prevalence of multiple sclerosis in Bulgaria. Neuroepidemiology. 1997;16(6):304-7. http://dx.doi.org/10.1159/000109701

34. Charalambidou E, Pantzaris M, Patrikios I. Multiple sclerosis in Cyprus: A fourteen year (2000-2014) epidemiological study. Am J Epidemiol Infect Dis. 2016;4(1):1-9.

35. Topcu G, Buchanan H, Aubeeluck A, Garip G. Caregiving in multiple sclerosis and quality of life: A meta-synthesis of qualitative research. Psychol Health. 2016 Jun;31(6):693-710. http://dx.doi.org/ 10.1080/08870446.2016.1139112

36. Brinar VV, Barun B. Challenges in multiple sclerosis; how to define occurrence of progression. Clin Neurol Neurosurg. 2013 Dec;115(Suppl 1):S30-4. http://dx.doi.org/10.1016/j.clineuro. 2013.09.017 
37. Szmurło D, Fundament T, Ziobro M, Kruntorádová K, Doležal T, Głogowski C. Costs of multiple sclerosis-extrapolation of Czech data to Polish patients. Expert Rev Pharmacoecon Outcomes Res. 2014 Jun;14(3):451-8. http://dx.doi.org/10.1586/14737167.2014.906305

38. Feys P, Giovannoni G, Dijsselbloem N, Centonze D, Eelen P, Andersen SL. The importance of a multi-disciplinary perspective and patient activation programmes in MS management. Mult Scler. 2016;22(2 Suppl):34-46. http://dx.doi.org/10.1177/1352458516650741

39. Kannel K, Alnek K, Vahter L, Gross-Paju K, Uibo R, Kisand KV. Changes in blood B cell-activating Factor (BAFF) levels in multiple sclerosis: A sign of treatment outcome. PLoS One. 2015 Nov;10(11):e0143393. http://dx.doi.org/10.1371/journal.pone.0143393

40. Soini E, Joutseno J, Sumelahti ML. Cost-utility of first-line disease-modifying treatments for relapsingremitting multiple sclerosis. Clin Ther. 2017 Mar;39(3):537-57. http://dx.doi.org/10.1016/j.clinthera. 2017.01 .028

41. Ruutiainen J, Viita AM, Hahl J, Sundell J, Nissinen H. Burden of illness in multiple sclerosis (DEFENSE) study: The costs and quality-of-life of Finnish patients with multiple sclerosis. J Med Econ. 2016;19(1):21-33. http://dx.doi.org/10.3111/13696998.2015.1086362

42. Rintala A, Häkkinen A, Paltamaa J. Ten-year follow-up of health-related quality of life among ambulatory persons with multiple sclerosis at baseline. Qual Life Res. 2016 Dec;25(12):3119-27. http:// dx.doi.org/10.1007/s11136-016-1347-x

43. Foulon S, Maura G, Dalichampt M, Alla F, Debouverie M, Moreau T, et al. Prevalence and mortality of patients with multiple sclerosis in France in 2012: A study based on French health insurance data. J Neurol. 2017 Jun;264(6):1185-92. http://dx.doi.org/10.1007/s00415-017-8513-0

44. Kwiatkowski A, Marissal JP, Pouyfaucon M, Vermersch P, Hautecoeur P, Dervaux B. Social participation in patients with multiple sclerosis: Correlations between disability and economic burden. MC Neurol. 2014 May 27; 14:115. http://dx.doi.org/10.1186/1471-2377-14-115

45. Höer A, Schiffhorst G, Zimmermann A, Fischaleck J, Gehrmann L, Ahrens H, et al. Multiple sclerosis in Germany: Data analysis of administrative prevalence and healthcare delivery in the statutory health system. BMC Health Serv Res. 2014;14:381. http://dx.doi.org/10.1186 /1472-6963-14-381

46. Ziemssen T, Engelmann U, Jahn S, Leptich A, Kern R, Hassoun L, et al. Rationale, design, and methods of a non-interventional study to establish safety, effectiveness, quality of life, cognition, health-related and work capacity data on Alemtuzumab in multiple sclerosis patients in Germany (TREAT-MS). BMC Neurol. 2016;16:109. http://dx.doi.org/10.1186/s12883-016-0629-9

47. Papathanasopoulos P, Gourzoulidou E, Messinis L, Georgiou V, Leotsinidis M. Prevalence and incidence of multiple sclerosis in western Greece: A 23-year survey. Neuroepidemiology. 2008;30(3):167-73. http://dx.doi.org/10.1159/000122334

48. Raggi A, Leonardi M. Burden and cost of neurological diseases: A European North-South comparison. Acta Neurol Scand. 2015 Jul;132(1):16-22. http://dx.doi.org/10.1111/ane.12339

49. Anagnostouli M, Katsavos S, Artemiadis A, Zacharis M, Argyrou P, Theotoka I, et al. Determinants of stigma in a cohort of hellenic patients suffering from multiple sclerosis: A cross-sectional study. BMC Neurol. 2016;16:101. http://dx.doi.org/10.1186/s12883-016-0621-4

50. Kefaliakos A, Pliakos I, Diomidous M. Managing the quality of life in patients with multiple sclerosis: A literature review. Stud Health Technol Inform. 2016;226:220-1.

51. Zsiros V, Fricska-Nagy Z, Füvesi J, Kincses ZT, Langane E, Paulik E, et al. Prevalence of multiple sclerosis in Csongrád County, Hungary. Acta Neurol Scand. 2014 Nov;130(5):277-82. http://dx.doi. org/10.1111/ane.12219

52. Péntek M, Gulácsi L, Rózsa C, Simó M, Iljicsov A, Komoly S, et al. Health status and costs of ambulatory patients with multiple sclerosis in Hungar. Ideggyogy Sz. 2010;65(9-10):316-24.

53. Fricska-Nagy Z, Füvesi J, Rózsa C, Komoly S, Jakab G, Csépány T, et al. The effects of fatigue, depression and the level of disability on the health-related quality of life of glatiramer acetate-treated relapsing-remitting patients with multiple sclerosis in Hungary. Mult Scler Relat Disord. 2016 May;7:26-32. http://dx.doi.org/10.1016/j.msard.2016.02.006

54. O'Connell K, Tubridy N, Hutchinson M, McGuigan C. Incidence of multiple sclerosis in the Republic of Ireland: A prospective population-based study. Mult Scler Relat Disord. 2017 Apr;13:75-80. http:// dx.doi.org/10.1016/j.msard.2017.02.010 
55. O'Connell K, Kelly SB, Fogarty E, Duggan M, Buckley L, Hutchinson M, et al. Economic costs associated with an MS relapse. Mult Scler Relat Disord. 2014 Nov;3(6):678-83. http://dx.doi. org/10.1016/j.msard.2014.09.002

56. Fogarty E, Walsh C, McGuigan C, Tubridy N, Barry M. Direct and indirect economic consequences of multiple sclerosis in Ireland. Appl Health Econ Health Policy. 2014 Dec;12(6):635-45. http://dx.doi. org/10.1007/s40258-014-0128-3

57. Fogarty E, Walsh C, Adams R, McGuigan C, Barry M, Tubridy N. Relating health-related Quality of Life to disability progression in multiple sclerosis, using the 5-level EQ-5D. Mult Scler. 2013 Aug;19(9):1190-6. http://dx.doi.org/10.1177/1352458512474860

58. Tintoré M, Alexander M, Costello K, Duddy M, Jones DE, Law N, et al. The state of multiple sclerosis: Current insight into the patient/health care provider relationship, treatment challenges, and satisfaction. Patient Prefer Adherence. 2016 Dec;11:33-45. http://dx.doi.org/10.2147/PPA.S115090

59. Gitto L. MS patients' awareness of disease and compliance with pharmacological treatments: Issues related to uncertainty in illness and health related quality of life. In: Sutton T, editor. Multiple sclerosis perspectives, clinical aspects and cognitive challenges. Hauppauge, NY: USA. Nova Publishers Incorporated; 2016. p. 49-86. Hardover: 978-1-63485-835-9.

60. Ponzio M, Gerzeli S, Brichetto G, Bezzini D, Mancardi GL, Zaratin P. Economic impact of multiple sclerosis in Italy: Focus on rehabilitation costs. Neurol Sci. 2015 Feb;36(2):227-34. http://dx.doi. org/10.1007/s10072-014-1925-z

61. Patti F, Amato MP, Trojano M, Solaro C, Pappalardo A, Zipoli V, et al. Multiple sclerosis in Italy: Costof-illness study. Neurol Sci. 2011 Oct;32(5):787-94. http://dx.doi.org/10.1007/s10072-011-0499-2

62. Solari A, Giordano A, Patti F, Grasso MG, Confalonieri P, Palmisano L, et al., PeNSAMI Project. Randomized controlled trial of a home based palliative approach for people with severe multiple sclerosis. Mult Scler. 2017 Apr:1352458517704078.

63. Duchovskiene N, Mickeviciene D, Jurkeviciene G, Dirziuviene B, Balnyte R. Factors associated with adherence to disease modifying therapy in multiple sclerosis: An observational survey from a referral center in Lithuania. Mult Scler Relat Disord. 2017 Apr;13:107-11. http://dx.doi.org/10.1016/j. msard.2017.02.016

64. Leonavicius R, Adomaitiene V. Features of sleep disturbances in multiple sclerosis patients. Psychiatr Danub. 2014 Sep;26(3):249-55.

65. Karampampa K, Gustavsson A, van Munster ET, Hupperts RM, Sanders EA, Mostert J, et al. Treatment experience, burden, and unmet needs (TRIBUNE) in Multiple Sclerosis study: The costs and utilities of MS patients in The Netherlands. J Med Econ. 2013 Jul;16(7):939-50. http://dx.doi.org/10.3111/1 3696998.2013.807267

66. Jongen PJ, Lemmens WA, Hoogervorst EL, Donders R. Glatiramer acetate treatment persistenceBut not adherence-In multiple sclerosis patients is predicted by health-related quality of life and selfefficacy: A prospective web-based patient-centred study (CAIR study). Health Qual Life Outcomes. 2017 Mar;15(1):50. http://dx.doi.org/10.1186/s12955-017-0622-z

67. Lunde HMB, Assmus J, Myhr KM, Bø L, Grytten N. Survival and cause of death in multiple sclerosis: A 60-year longitudinal population study. J Neurol Neurosurg Psychiatry. 2017 Aug;88(8):621-625. doi: 10.1136/jnnp-2016-315238.

68. Cortese M, Riise T, Bjørnevik K, Myhr KM, Multiple Sclerosis Conscript Service Database Study Group. Body size and physical exercise, and the risk of multiple sclerosis. Mult Scler. 2017 Mar 1; 1352458517699289. doi: 10.1177/1352458517699289

69. Klevan G, Jacobsen CO, Aarseth JH, Myhr KM, Nyland H, Glad S, et al. Health related quality of life in patients recently diagnosed with multiple sclerosis. Acta Neurol Scand 2014 Jan;129(1):21-6. http:// dx.doi.org/10.1111/ane.12142

70. Brola W, Sobolewski P, Flaga S, Fudala M, Jantarski K. Increasing prevalence and incidence of multiple sclerosis in Poland. Neurochir Pol. 2017 Jan-Feb;51(1):82-5. http://dx.doi.org/10.1016/j.pjnns. 2016.11 .005

71. Malinowski KP, Kawalec PP, Moćko P. Indirect costs of absenteeism due to rheumatoid arthritis, psoriasis, multiple sclerosis, insulin-dependent diabetes mellitus, and ulcerative colitis in 2012. Expert Rev Pharmacoecon Outcomes Res. 2016;16(2):295-303. http://dx.doi.org/10.1586/147371 67.2016 .1085802 
72. Brola W, Sobolewski P, Fudala M, Flaga S, Jantarski K, Ryglewicz D, et al. Self-reported quality of life in multiple sclerosis patients: Preliminary results based on the Polish MS Registry. Patient Prefer Adherence. 2016 Aug;10:1647-56. http://dx.doi.org/10.2147/PPA.S109520

73. Wilski M, Tasiemski T. Health-related quality of life in multiple sclerosis: Role of cognitive appraisals of self, illness and treatment. Qual Life Res. 2016 Jul;25(7):1761-70. http://dx.doi.org/10.1007/ s11136-015-1204-3

74. de Sá. Epidemiology of multiple sclerosis in Portugal and Spain. Rev Neurol. 2010 Oct; 51(7):387-92.

75. Viana P, Rodrigues E, Fernandes C, Matas A, Barreto R, Mendonça M, et al. Chronic insomnia disorder in multiple sclerosis-A Portuguese multicentre study on prevalence, subtypes, associated factors and impact on quality of life. Mult Scler Relat Disord. 2015 Sep;4(5):477-83.

76. Becuş T, Popoviciu L. Epidemiologic survey of multiple sclerosis in Mureş County, Romania. Rom J Neurol Psychiatry. 1994 Apr-Jun;32(2):115-22.

77. Petrescu A, Verdeş F. Epidemiology of multiple sclerosis in Romania. Neurol Psychiatr (Bucur). 1989 Oct-Dec;27(4):261-71.

78. Flachenecker P, Khil L, Bergmann S, Kowalewski M, Pascu I, Pérez-Miralles F, et al. Development and pilot phase of a European MS register. J Neurol. 2010 Oct;257(10):1620-27. http://dx.doi. org/10.1007/s00415-010-5578-4

79. Prokopova B, Hlavacova N, Vlcek M, Penesova A, Grunnerova L, Garafova A, et al. Early cognitive impairment along with decreased stress-induced BDNF in male and female patients with newly diagnosed multiple sclerosis. J Neuroimmunol. 2017 Jan;302:34-40. http://dx.doi.org/10.1016/j. jneuroim.2016.11.007

80. Pšenková M, Mackovičová S, Palúch A, Foltánová T, Petrová L. Economic burden of multiple sclerosis in Slovakia. Eur Med Health Pharm J. 2015;3:12.

81. Gavelova M, Nagyova I, Rosenberger J, Krokavcova M, Gdovinova Z, Groothoff JW, et al. Importance of an individual's evaluation of functional status for health-related quality of life in patients with multiple sclerosis. Disabil Health J. 2015;8(3):372-9. http://dx.doi.org/10.1016/j. dhjo.2015.02.006

82. Rasova K, Freeman J, Martinkova P, Pavlikova M, Cattaneo D, Jonsdottir J, et al. The organisation of physiotherapy for people with multiple sclerosis across Europe: A multicentre questionnaire survey. BMC Health Serv Res. 2016 Oct 6;16(1):552. http://dx.doi.org/10.1186/s12913-016-1750-6

83. Ožura A, Sega S. Profile of depression, experienced distress and capacity for coping with stress in multiple sclerosis patients_A different perspective. Clin Neurol Neurosurg. 2013 Dec;115(Suppl 1):S12-16. http://dx.doi.org/10.1016/j.clineuro.2013.09.014

84. Meca-Lallana J, Muñoz D, Oreja-Guevara C, Olascoaga J, Meca V, Pato A, et al. Spanish Registry of patients with multiple sclerosis treated with fingolimod (GILENYA Registry): Safety and effectiveness after three years of registry. ECTRIMS Online Library. Meca-Lallana J. Sep 16, 2016; 145853.

85. Candeliere-Merlicco A, Valero-Delgado F, Martínez-Vidal S, Lastres-Arias M del C, Aparicio-Castro E, Toledo-Romero F, et al. Prevalence of multiple sclerosis in Health District III, Murcia, Spain. Mult Scler Relat Disord. 2016 Sep;9:31-5. http://dx.doi.org/10.1016/j.msard.2016.06.003

86. Oliva-Moreno J, Trapero-Bertran M, Peña-Longobardo LM, Del Pozo-Rubio R. The valuation of informal care in cost-of-illness studies: A systematic review. Pharmacoeconomics. 2017;35(3):331-45. http://dx.doi.org/10.1007/s40273-016-0468-y

87. Ayuso GI. Multiple sclerosis: Socioeconomic effects and impact on quality of life. Med Clin (Barc). 2014 Dec;143(Suppl 3):7-12. http://dx.doi.org/10.1016/S0025-7753(15)30003-8

88. Sanz-Granda A, Garcia-Jurado L, Polanco-Sanchez C. Budget impact analysis of the first-line treatment of relapsing remitting multiple sclerosis in Spain. Rev Neurol. 2012 Apr;54(7):446-7.

89. Svenningsson A, Salzer J, Vågberg M, Sundström P, Svenningsson A. Increasing prevalence of multiple sclerosis in Västerbotten County of Sweden. Acta Neurol Scand. 2015 Dec;132(6):389-94. http:// dx.doi.org/10.1111/ane.12408

90. Gyllensten H, Wiberg M, Alexanderson K, Norlund A, Friberg E, Hillert J, et al. Costs of illness of multiplesclerosis in Sweden: A population-based register study of people of working age. Eur J Health Econ. 2017 May 9. doi: 10.1007/s10198-017-0894-6 
91. Mäurer M, Comi G, Freedman MS, Kappos L, Olsson TP, Wolinsky JS, et al. Multiple sclerosis relapses are associated with increased fatigue and reduced health-related quality of life-A post hoc analysis of the TEMSO and TOWER studies. Mult Scler Relat Disord. 2016 May;7:33-40. http://dx.doi. org/10.1016/j.msard.2016.02.012

92. Egger S, Müller M, Bigler S, Spirig R. Understanding needs of people with Multiple Sclerosis. Perspective of patients and significant others in the German-speaking part of Switzerland. Pflege. 2012 Oct;25(5):329-41. http://dx.doi.org/10.1024/1012-5302/a000229

93. Zecca C, Riccitelli GC, Calabrese P, Pravatà E, Candrian U, Guttmann CR, et al. Treatment satisfaction, adherence and behavioral assessment in patients de-escalating from natalizumab to interferon $\beta$. BMC Neurol. 2014 Feb;14:38. http://dx.doi.org/10.1186/1471-2377-14-38

94. Mackenzie IS, Morant SV, Bloomfield GA, MacDonald TM, O'Riordan J. Incidence and prevalence of multiple sclerosis in the UK 1990-2010: A descriptive study in the General Practice Research Database. J Neurol Neurosurg Psychiatry. 2014 Jan;85(1):76-84. http://dx.doi.org/10.1136/jnnp-2013-305450

95. Hawton A, Green C. Health utilities for multiple sclerosis. Value Health. 2016 Jun;19(4):460-8. http://dx.doi.org/10.1016/j.jval.2016.01.002 